\title{
Relationship between motivation, learning habit and overall results of polytechnic mechanical engineering student in semester two
}

\author{
Akasyah Mohd Khathri ${ }^{1}$, Che Haspu Robiah Daud ${ }^{2}$ \\ ${ }^{12}$ Politeknik Sultan Mizan Zainal Abidin
}

\begin{tabular}{l} 
Article Info \\
\hline Article history: \\
Received Dec $2^{\text {rd }}, 2018$ \\
Revised Dec $6^{\text {th }}, 2018$ \\
Accepted Dec $8^{\text {th }}, 2018$ \\
\hline
\end{tabular}

\section{Keyword:}

Motivation

Learning Habit

Overall Results

Mechanical Engineering

\begin{abstract}
This study aims to determine the relationship between motivations, learning habit and overall achievement in the second semester of Mechanical Engineering students at Terengganu Polytechnic. The study also aims to identify the differences in learning by gender at early achievement in the previous semester. To achieve this goal, the method of survey is conducted. Samples consisted of 196 students in second semester out of four programs in Mechanical Engineering Department. The study instrument used was Selmes Learning Inventory which presented four learning styles, namely deep-style, surface-style, well-organized style and diligent. The fifth style of learning, motivational style has been modified to measure the internal and external motivation. Data collected were analyzed descriptively and inferred using SPSS software. The results of the descriptive analysis found that students had high internal motivation as compared to external motivation as well as practicing surface style and deeper style than planned and diligent style. Inferential analysis results found that the overall achievement of the second semesters had a relationship with the in-depth learning style, effort and planning. There is a significant relationship between deep learning style and internal motivation. There was no significant difference in learning habit by gender and early achievement. The implication of this study is that motivation plays an important role in determining the choice of learning methods practiced by the students.
\end{abstract}

(C) 2018 The Authors. Published by Redwhitepress

This is an open access article under the CC BY-NC-SA license (https://creativecommons.org/licenses/by-nc-sa/4.0/

\section{Corresponding Author:}

Akasyah Mohd Khathri,

Politeknik Sultan Mizan Zainal Abidin

Email: akasyah.mk@gmail.com

\section{Introduction}

Industrial in Malaysia nowadays needs more semi-skilled manpower especially in mechanical engineering. This field requires those who are able to assimilate and assess facts accurately and scientifically. This engineering-based learning is designed to achieve its goals, which is to enhance the students' knowledge, skills and enthusiasm to achieve excellent results. They are expected to be able to use the learned knowledge effectively to solve problems and to have sufficient preparation to further their studies and to work productively in their careers.

In order to realize the goal of engineering learning, various modules have been designed to generate students' interest, attitudes and motivation, thereby enhancing their achievement. For example, the Department of Polytechnic and Community College (JPPKK) has created CIDOS and MOOC modules in an effort to improve the quality of achievement in line with the 4.0 industrial revolution (IR4.0). At the departmental level, various courses are organized such as mathematical clinics and Outcome-based learning 
(OBE) aimed at improving the quality of student achievement. This will indirectly encourage active involvement among students in the classroom.

Various causal factors have been raised by education experts about the deterioration and problems in student learning. Among the factors are early achievement, basic skills, interest, attitudes, motivation and problem solving skills (Hamid, 1998). Another factor is the inconsistency of teaching approaches received with student learning needs and styles where students do not know how to learn effectively. These factors are among the factors that are believed to have resulted in a phenomenon in the deterioration of achievement in the subjects taken in polytechnics. Therefore, management and educators should play a role in addressing the problem to improve student performance, especially in the field of mechanical engineering.

\section{Literature Review}

The study conducted by (Bozkurt, 2013) is to determine the links between pre-service teachers' metacognitive level, learning habits and their achievement of history class. In the study, three section data of learning have been proposed, namely the metacognition activity inventory, learning style inventory and history achievement test were taken. The sample consists of 175 pre-service teachers that were studying in primary teaching program in Faculty of Education, Mustafa Kemal University. The findings show there was a significant positive correlation between student's achievement and participant learning styles, but a negative relationship between achievement and passive learning style. In addition, a significant positive correlation was found between teachers 'levels of metacognition and independent, collaborative, competitive, and participant learning styles.

Jahanbakhsh (2012) study the relationship between learning styles with achievement based on program learn by student in girl's high school. By using Felder and Solomon Learning Style Index (FLSI) as their questionnaire, the results found that learning styles shows inline correlations with educational achievement of students especially in mathematic science as major course. Educational achievement of students who study in science shows parallel correspondence with active-reflective learning styles. In students with empirical science, their end result shows highly significant correlation with input dimesion and understand dimension of revision (Jahanbakhsh, 2012).

Yalani \& Bakar (2017) study internal and external factors for English proficiency among IPTS student in Selangor. Respondents of the study consisted of 185 undergraduate and graduate students from the Faculty of Management. The findings show that all factors have a positive correlation with the English proficiency level among students in the IPTS. This shows that the collaboration and involvement of all parties is very important in increasing the English proficiency level apart from the student's internal factors (Yalani \& Bakar, 2017).

Bozkurt (2013) explore the relationship between of metacognition, learning styles and academic success of pre-service teachers' levels subject. In his finding, there was a positive correlation between teachers' achievement and student learning styles, but a negative in achievement and passive learning style. In addition, a significant positive correlation was found between teachers 'levels of metacognition and independent, collaborative, competitive, and participant learning styles. Therefore in his paper, individuals are not depending on others. They should control their own learning styles (Bozkurt, 2013).

Biçer (2014) was study relationship of learning styles and achievement of foreign language preparatory school students in Turkey. In his study, raw data was obtained from a learning styles inventory, students' placement exam scores and average exam scores from 139 students and 12 instructors. The results shows learning styles did not effect by students' gender and the last place of their study. Futhermore, The group of students with the same learning method has resulted in the same examination results (Biçer, 2014).

Overall, previous studies reported that there was no difference in learning style by gender. At the same time, positive relationships between learning habits and academic achievement are also inconsistent. However, previous studies show that there is a correlation between learning style and motivation, that is, deep learning style has to do with internal motivation.

\section{Problem Statement}

Low performance problems in some courses, especially those involving engineering calculations, should be taken into account accordingly. This lack of achievement can lead to a lack of opportunities to pursue higher education. Hence, many parties have expressed the various factors that cause the weaknesses in which one of these factors is the student learning style.

Individual learning style is important in improving academic performance. This is because there are differences in the nature of individual learning that should be addressed by the lecturers. However, what 
happens in the classroom during the teaching and learning process is that students are told what they should learn rather than how they should study. Lecturers have less emphasis on the students on the appropriate learning style and should be practiced by them. In this case, students may not practice appropriate and effective learning styles. Hence, it is important for lecturers to identify the learning habits of students and to help them practice learning habits that can improve their achievement to a level of excellence.

In education, lecturers play a role in knowing and understanding individual learning styles because an effective learning style for a student may be inappropriate for other students. It is therefore imperative for a lecturer to introduce various learning styles to ensure the suitability exists for all students involved. Students should also know what learning style is appropriate for them. In this case, lecturers can play a role in helping students to understand the trends and the ways in which they learn to improve the effectiveness of learning, thus producing good results.

Since learning style is one of the factors that are related to student achievement, the researcher feels it is necessary to study more deeply in this aspect. Studies on learning styles are so important in improving student learning quality.

\section{Theoretical Concept}

(Susabda, 1992) has studied the learning style according to the initial achievement of the students. The findings show that excellent and weak students have different learning habits. Meanwhile, the results obtained by (Omar, Mohamad, \& Paimin, 2015) show that the various factors of the study program affect the student learning style. However, in this study, researchers are more focused on large areas of mechanical engineering with four small programs in them. (Orhun, 2012) suggests that the improvement of success in academic achievement can be achieved by strengthening the student learning approach. Students who use deep approaches have high internal motivation towards subjects. The focus of learning is to understand the lessons. On the other hand, students using surface approaches have the 'fear of failure' motivation and external motivation. Indirectly it reveals that student motivation is critical to the success of learning.

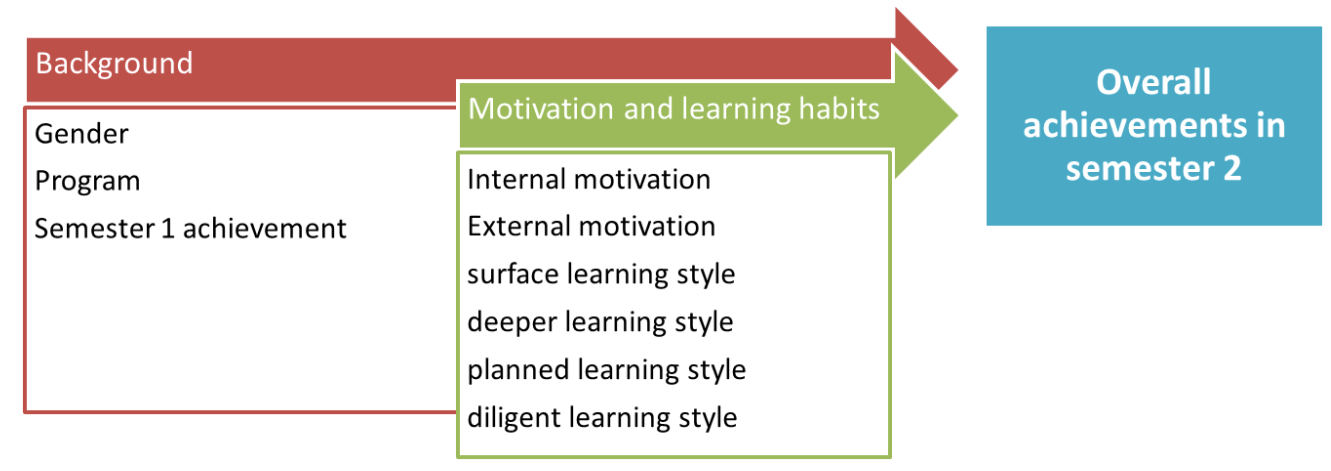

Figure 1: Theoritical framework

A conceptual framework of the study has been adapted from the (Bryant, 1974) model and the findings obtained (as shown in Figure 1). In the conceptual framework of the study, it is assumed that gender, ethnic and early achievement factors influence motivation and learning styles. An additional element is a program offered in mechanical engineering to see the difference between each other. Next, motivation and learning habits will influence the academic achievement of students

\section{Objective of the study}

The purposes of this study are:

1. Determining the relationship between motivation with learning style and second semester achievement.

2. Determine the differences in learning styles by gender, program and early achievement.

\section{Hypothesis of the Study}

Hypotheses of this study are:

1. There is no significant relationship between motivation and learning style

2. There is no relationship between the learning style and the achievement of the second semester.

3. There is no significant difference between learning style by sex.

4. There is no significant difference between learning based on early achievement 


\section{Research Method}

This study was conducted in a correlation-based survey. This method is appropriate with the purpose of the study to see the relationship between motivation with learning habits and overall achievement. To obtain information or data about the variables studied, a questionnaire was used. This research tool has tested its reliability and reliability first in pilot studies. This is to ensure that the research tool is suitable for this study.

The sample of this study consists of 196 students of the semester two field Diploma of Mechanical Engineering (DKM), Diploma of Mechanical-Mechatronics Engineering (DEM), Diploma of Mechanical Engineering-Automotive (DAD) and Diploma of Mechanical Engineering-Manufacturing (DTP) at Terengganu State Polytechnic. Although there are four Polytechnic in Terengganu, only Polytechnic Sultan Mizan Zainal Abidin (PSMZA) only offers mechanical engineering programs. Therefore, this study was conducted entirely in the polytechnics.

The total number of second semester students from four mechanical engineering programs is 400 . Based on the sample size determination table proposed by (Krejcie, 1970), the sample size required for the population was 196. The sample consisted of 196 students from four randomly chosen programs. Samples consisted of male and female students and achievement groups. The majority of students are from the Malay race and the rest of the Indians. Most students comprise excellent students who earn an average point value of one semester above 3.0. This is because most students with HPNM 3.0 are eligible to continue their studies at a university degree.

Instrument of Study

In this study, the instrument used is a questionnaire consisting of two parts, namely Part A contains student information and Part B is a questionnaire adapted from the School Inventory of Learning by (Selmes, 1987). For this study, four learning styles are included. The selection of this toolkit is based on its widespread use across the globe in various aspects of education. In addition, the instrument was also found to be compatible with the Polytechnic situation and can be used to identify the student learning styles for a subject.

A pilot study was conducted on 30 Diploma in Mechanical Engineering students, PSMZA. The results were analyzed using Alpha Cronbach method. The value of the internal consistency reliability coefficient obtained for each dimension of learning style is shown in Table 1. It is found that Alpha coefficient values for each dimension are good and appropriate to be used in the study to determine the relationship between learning style and overall achievement.

Table 1: Cronbach's Alpha reliability item

\begin{tabular}{llll}
\hline No & Learning habit & $\mathrm{N}$ & Alpha \\
\hline 1 & Internal motivation & 4 & 0.623 \\
2 & External motivation & 4 & 0.848 \\
3 & surface learning style & 12 & 0.714 \\
4 & deeper learning style & 12 & 0.909 \\
5 & planned learning style & 12 & 0.908 \\
6 & diligent learning style & 9 & 0.916 \\
\hline
\end{tabular}

The data collected through questionnaire and analyzed using computer assistance. The computer software used in this study is the Statistical Package for Social Science (SPSS PC version 7.5). The analysis process involves two types of analysis, namely descriptive analysis and inference analysis. Descriptive analysis is used to describe information about respondents' profiles such as gender, program and initial achievement of students. In addition, descriptive analysis is also used to describe the learning style and the characteristics of the learning practiced by the students. Statistics used are frequency, percentage, mean and standard deviation.

To test the null hypothesis, inference analysis is used. The inference analysis used is Pearson correlation test and t-test. Pearson correlation test was used in this study to test the null hypothesis about the relationship between motivation with learning style and achievement. In this study, t-test was used to test the null 
hypothesis to see the difference in mean learning habits based on gender, program and initial achievement. For both tests, significant levels are set at 0.05 levels.

\section{Results and Discussion}

The findings are described in the form of descriptive and inferential to answer the questions and hypotheses of the study.

\section{Student's Learning Habits}

Table 2 and 3 show the results of thestudents motivation and learning habits analysis adopted by the students during the study.

Table 2: Students motivation

\begin{tabular}{lllll}
\hline & Student Motivation & $\mathrm{N}$ & mean score & S. Deviation \\
\hline 1 & Internal motivation & 196 & 17.15 & 1.64 \\
2 & External motivation & 196 & 16.40 & 1.80 \\
\hline
\end{tabular}

Table 3: Learning habits among students

\begin{tabular}{lllll}
\hline & Learning habit & $\mathrm{N}$ & mean & S. Deviation \\
\hline 3 & surface learning style & 196 & 46.21 & 4.68 \\
4 & deeper learning style & 196 & 44.96 & 6.38 \\
5 & planned learning style & 196 & 46.44 & 6.06 \\
6 & diligent learning style & 196 & 31.77 & 6.40 \\
\hline
\end{tabular}

Refer to table 3, the high mean score is for surface style (46.21) and planned style (46.44) followed by deeper style (44.96) and diligent style of effort (31.77). This finding demonstrates that planned and surface styles are more practiced than deeper and diligent styles. Overall, the mean difference is small and this suggests that student's practice various learning styles and is not bound to a learning style alone, ie planned or surface.

\section{Internal and External Motivation}

Table 4 shows the results of analysis of eight items to measure learning motivation (internal and external). A high mean score is obtained (refer to items 2, 3 and 4) for the characteristics of students who have motivated learning through their own motivation (internal motivation). While lower mean scores (refer to items 1,5 , and 6) are those who learn due to lecturer and friend encouragement (external motivation). Overall, students have a high internal motivation boost compared to external motivation.

Table 4: Internal and external motivation

\begin{tabular}{lllll}
\hline & Internal motivation & $\mathrm{N}$ & mean & S. Deviation \\
\hline 1 & Restless when left behind in the given assignment & 196 & 3.85 & 0.63 \\
2 & Want to get a high score from other students & 196 & 4.40 & 0.49 \\
3 & Feel shy when it does not perform well & 196 & 4.70 & 0.64 \\
4 & Want to do a better job than other students & 196 & 4.20 & 0.40 \\
\hline & External motivation & $\mathrm{N}$ & mean & S. Deviation \\
\hline 5 & Want lecturers to know that I am a hopeful student & 196 & 3.90 & 0.54 \\
6 & Feel free to compete with other students in the assignment & 196 & 3.90 & 0.53 \\
7 & Would like to point out to the lecturer that I have tried my best & 196 & 4.40 & 0.49 \\
8 & Feeling worried when lecturers criticized my assignment & 196 & 4.20 & 0.60 \\
\hline
\end{tabular}




\section{Surface Learning Style}

Table 5: Surface learning style analysis

\begin{tabular}{lllll}
\hline & Surface learning style & N & Mean & S. Deviation \\
\hline 1 & Requires a detailed description of the work given & 196 & 4.50 & 0.50 \\
2 & Requires a detailed description of what needs to be revised & 196 & 4.40 & 0.49 \\
3 & Often try to recall what is written in the note & 196 & 3.80 & 0.87 \\
4 & Requires a detailed description of what to do in the reading & 196 & 4.09 & 0.54 \\
& Requires a detailed description of what to do during the & & & \\
5 & review & 196 & 4.38 & 0.49 \\
6 & Focus on every fact when reading & 196 & 3.81 & 0.60 \\
7 & Make notes only important content that needs to be learned & 196 & 3.76 & 1.02 \\
8 & Focusing on facts when reviewing & 196 & 3.79 & 0.74 \\
9 & Trying to memorize all the facts during the review & 196 & 3.48 & 0.79 \\
10 & Try memorizing all notes when reading & 196 & 2.99 & 0.89 \\
11 & Write notes that mostly contain factual information only & 196 & 3.60 & 0.80 \\
12 & Arranging most notes systematically & 196 & 3.61 & 0.92 \\
\hline
\end{tabular}

Table 5 shows the mean score of surface learning style features. The high mean score in items $1,2,4$ and 5 indicates that students who practice the surface style need help from lecturers about the work to be done. From the lower mean scores on items 3, 6, 7, 8 and 9 prove that some of the students try to memorize all the facts when reviewing and understanding the contents of the course surface only. They also cannot organize notes systematically.

\section{Deeper Learning Style}

Based on Table 6, the highest mean score in deeper learning styles are items 1, 2 and 5. This indicates that students have a high interest in the content of the lesson and try to understand it in depth. They try to summarize the rules used when solving the problem. However, some students do not seek to diversify the materials and do not give their own opinions when they have the chance. They are more dependent on materials given by lecturers. This refers to items $6,7,8,9,10,11$ and 12 .

Table 6. Deeper learning style analysis

\begin{tabular}{lllll}
\hline & Deeper learning style & $\mathrm{N}$ & mean & $\begin{array}{l}\text { S. } \\
\text { Deviation }\end{array}$ \\
\hline 1 & Discuss with other friends a topic when reviewing & 196 & 4.01 & 0.63 \\
2 & Summarize important material when making notes & 196 & 4.01 & 0.63 \\
3 & Identifying implicit meaning when reading a note & 196 & 3.71 & 0.78 \\
4 & Summarizes the rules used when solving the problem & 196 & 3.80 & 0.75 \\
5 & Summarizes notes while reviewing & 196 & 4.01 & 0.77 \\
6 & Try various ways while reviewing & 196 & 3.80 & 0.87 \\
7 & Using a variety of ways while answering questions & 196 & 3.82 & 0.75 \\
& Deciphering the relevance of the various ways found & & & \\
8 & during reading & 196 & 3.40 & 0.67 \\
9 & Ask yourself some questions during revision & 196 & 3.80 & 0.59 \\
10 & Merge notes from various sources & 196 & 3.60 & 0.66 \\
11 & Give your own opinion when possible & 196 & 3.55 & 0.81 \\
12 & Inserting your own view while writing a note & 196 & 3.47 & 1.04 \\
\hline
\end{tabular}

\section{Planned Learning Style}

Table 7 shows the analysis of the characteristics of planned learning. Generally, the mean score is at a low level of items 5, 6, 10, and 12. It proves that the students like to delay the time available for the review. In other words, students do not plan on learning time effectively and are not ready to take the exam. However, they devised to devote enough time to make their own notes and plan tasks that are adequately perfected (refer to items 2 and 11). 
Table 7. Planned learning style analysis

\begin{tabular}{lllll}
\hline & Planned learning style & N & mean & S. Deviation \\
\hline 1 & Draw answers first before answering test questions. & 196 & 3.90 & 0.82 \\
2 & Allocate enough time to make notes yourself. & 196 & 4.00 & 1.01 \\
3 & Try reading all the notes as fast as possible & 196 & 3.90 & 0.54 \\
4 & Allocate enough time to make the necessary notes. & 196 & 3.90 & 0.70 \\
5 & Try to make notes as quickly as possible & 196 & 3.70 & 0.64 \\
6 & try to make revisions as soon as possible & 196 & 3.60 & 0.49 \\
7 & Allocate sufficient time to create additional references & 196 & 3.90 & 0.83 \\
8 & Allocate sufficient time to revise lecturer note. & 196 & 3.91 & 0.70 \\
9 & Divide the time to review the lesson in its own way. & 196 & 3.90 & 0.70 \\
10 & Planning to revisit lessons learned. & 196 & 3.81 & 0.60 \\
11 & To plan the assignment perfectly suited & 196 & 4.10 & 0.70 \\
& Answer the test questions without taking into account & & & \\
12 & what was remembered first. & 196 & 3.80 & 0.75 \\
\hline
\end{tabular}

\section{Diligent Learning Style}

Table 8 shows the mean of nine characterized learning style styles. On average, mechanical engineering students at Terengganu Polytechnic highlighted this feature. However, there are some students who are always trying to find the cause of weakness when the performance drops and fixes it immediately. In addition, they are trying to make additional references from several books and prepare a task as soon as possible. This refers to items 1, 2, 3 and 5. The results of the analysis also found that some of the students liked to wait for the lecturers to give directions without trying to review and practice on their own as in items $6,7,8$ and 9. This finding is in line with the results obtained for the characteristics of the students who practice the above surface learning. Typically, these students are those who are weak because students are less likely to require the instruction of a lecturer to do a task.

Table 8. Planned learning style analysis

\begin{tabular}{lllll}
\hline \multicolumn{2}{l}{ Diligent learning style } & & & S. \\
\hline & Looking for a cause of weakness when performance & & mean & Deviation \\
1 & decreases. & 196 & 3.89 & 0.84 \\
2 & Using several books to create an assignment & 196 & 3.80 & 0.87 \\
3 & Prepare a task as soon as possible & 196 & 3.92 & 1.13 \\
4 & Make a note when there is a chance & 196 & 3.60 & 0.91 \\
5 & Trying to solve learning problems even though it's difficult & 196 & 3.90 & 0.71 \\
& Read what's necessary without waiting for the lecturer's & & & \\
6 & instructions & 196 & 3.02 & 0.92 \\
7 & Review all topics without waiting for lecturer's instructions & 196 & 3.14 & 1.14 \\
8 & Complete the task ahead of time. & 196 & 3.19 & 0.87 \\
9 & Make various exercises independently & 196 & 3.31 & 0.90 \\
\hline
\end{tabular}

\section{Learning Relationship with Motivation}

Table 9 shows an analysis of motivation correlation with learning style. There is a significant relationship between internal motivation and surface learning style. There is also significant relationship between external motivation and surface learning styles.

Table 9: Learning relationship with motivation analysis

\begin{tabular}{llll}
\hline & Student Motivation & Internal motivation & External motivation \\
\hline & Learning habits & $r$ & $r$ \\
\hline 1 & surface learning style & $0.133^{*}$ & $0.154^{*}$ \\
2 & deeper learning style & 0.123 & 0.196 \\
3 & planned learning style & 0.161 & 0.052 \\
4 & diligent learning style & 0.203 & 0.101 \\
${ }^{*}$ Correlation is significant at the 0.05 level & &
\end{tabular}




\section{Learning Relationship with Overall Achievement}

The findings in Table 10 show that there are a significant difference between the surface learning, deeper learning, planned learning and diligent learning style with achievement. However, the value of $r$ is low and this shows a relatively weak relationship.

Table 10: Learning relationship with motivation analysis

\begin{tabular}{llll}
\hline Learning habits & $n$ & $r$ & $p$ \\
\hline surface learning style & 196 & $0.133^{*}$ & 0.154 \\
deeper learning style & 196 & $0.123^{*}$ & 0.196 \\
planned learning style & 196 & $0.161^{*}$ & 0.052 \\
diligent learning style & 196 & $0.203^{*}$ & 0.101 \\
${ }^{*}$ Correlation is significant at the & 0.05 plevel & &
\end{tabular}

\section{Education Style Difference by Gender}

The findings of Table 11 show that there is a significant difference in the style of planned learning by gender. However, the findings show that there is no significant difference in surface learning styles, depth and persistence of gender. Overall, the mean difference in learning style between male and female students is small. This is allign with (Biçer, 2014) research that The distribution of the learning styles did not differ according to students' gender and the high schools they had graduated. Therefore, gender factors do not affect the learning style.

Table 11: Education style difference by gender analysis

\begin{tabular}{|c|c|c|c|c|c|}
\hline Learning habits & Jantina & $n$ & mean & $t$ & $p$ \\
\hline \multirow{2}{*}{ surface learning style } & Lelaki & 139 & 46.45 & \multirow{2}{*}{-0.55} & \multirow{2}{*}{0.59} \\
\hline & Perempuan & 57 & 44.61 & & \\
\hline \multirow{2}{*}{ deeper learning style } & Lelaki & 139 & 45.26 & \multirow{2}{*}{1.05} & \multirow{2}{*}{0.29} \\
\hline & Perempuan & 57 & 44.23 & & \\
\hline \multirow{2}{*}{ planned learning style } & Lelaki & 139 & 45.59 & \multirow{2}{*}{-0.01} & \multirow{2}{*}{0.99} \\
\hline & Perempuan & 57 & 46.07 & & \\
\hline \multirow[b]{2}{*}{ diligent learning style } & Lelaki & 139 & 32.12 & \multirow[b]{2}{*}{1.52} & \multirow[b]{2}{*}{0.14} \\
\hline & Perempuan & 57 & 30.91 & & \\
\hline
\end{tabular}

${ }^{*}$ Correlation is significant at the $0.05 \mathrm{plevel}$

\section{Differences in Learning Styles by Early Achievement}

The t-test results shown in Table 12 found that there were no significant differences in surface learning styles, depth, planning and diligent in the early stages achievement. This finding suggests that excellent students and students are weak in practicing the same learning style. Therefore, the early achievement factor does not affect the learning habits.

Table 12: Differences in Learning Styles by Early Achievementanalysis

\begin{tabular}{lllllll}
\hline \multicolumn{2}{l}{ Learning habits } & $\begin{array}{l}\text { Early } \\
\text { achievement }\end{array}$ & $n$ & mean & $t$ & $p$ \\
\hline surface & learning & Excellent & 39 & 39.38 & 0.16 & 0.88 \\
style & & Weak & 157 & 47.9 & & \\
deeper & learning & Excellent & 39 & 34.77 & 0.74 & 0.46 \\
style & & Weak & 157 & 47.5 & & \\
planned & learning & Excellent & 39 & 36.53 & -0.84 & 0.40 \\
style & & Weak & 157 & 48.9 & & \\
diligent & learning & Excellent & 39 & 31.43 & 0.76 & 0.45 \\
style & & Weak & 157 & 34.25 & & \\
\hline
\end{tabular}

${ }^{*}$ Correlation is significant at the $0.05 \mathrm{plevel}$ 


\section{Discussion}

Appropriate and effective learning habits if practiced can help students achieve high achievement in overall achievement. The result of the research shows that motivation has relation with the practice of student learning style. Internally motivated student's practice deep learning and these findings support from previous studies. Information about learning habits can also help lecturers identify the learning habits of students so that the lessons delivered meet the differences that each individual has. With that, the teaching and learning process can run smoothly and effectively to improve the quality and quality of education in the face of the challenges of science and technology. In addition, students can also understand their own tendencies, strengths and weaknesses in the learning style they practice. This can be a driving force for developing new learning habits that can improve their achievement in the coming exams.

\section{Conclusion}

The findings showed that students practiced various learning not bound to one learning style. Students have more internal motivation when compared with external motivation. There is a relationship between the learning style and the type of motivation. Motivation is motivated to prioritize in-depth learning when compared with external motivated learners who are more likely to have surface learning styles. However, from the correlation value, the relationship is very modest.

\section{References}

Biçer, D. (2014). The Effect of Students' and Instructors' Learning Styles on Achievement of Foreign Language Preparatory School Students. Procedia - Social and Behavioral Sciences, 141, 382-386. doi:10.1016/j.sbspro.2014.05.067

Bozkurt, N. (2013). An Examination of the Links between Pre-service Teacher's Metacognitive Level, Learning Styles and their Achievement of History Class. Procedia - Social and Behavioral Sciences, 93, 1634-1640. doi:10.1016/j.sbspro.2013.10.093

Bryant, E. G. (1974). Associations between educational outcomes and background variables. Washington D.C.: National Assessment of Educational Progress.

Hamid, S. (1998). Hubungan minat, sikap, motivasi dan kemahiran asas dengan pencapaian pelajar dalam matematik. Universiti Kebangsaan Malaysia. Bangi, Latihan Ilmiah.

Jahanbakhsh, R. (2012). Learning Styles and Academic Achievement: a Case Study of Iranian High School Girl's Students. Procedia - Social and Behavioral Sciences, 51, 1030-1034. doi:10.1016/j.sbspro.2012.08.282

Krejcie, R. V. (1970). Determining sample size for research activities. Educational and psychological measurement, $30,4$.

Omar, N., Mohamad, M. M., \& Paimin, A. N. (2015). Dimension of Learning Styles and Students' Academic Achievement. Procedia - Social and Behavioral Sciences, 204, 172-182. doi:10.1016/j.sbspro.2015.08.130

Orhun, N. (2012). The Relationship Between Learning Styles and Achievement in Calculus Course for Engineering Students. Procedia - Social and Behavioral Sciences, 47, 638-642. doi: $10.1016 /$ j.sbspro.2012.06.710

Selmes, I. P. (1987). Improving study skills: Changing perspective in education. Great Britain: Hodder and Stoughton Ltd.

Susabda, E. (1992). The relationship between matched/mismatched students learning styles to faculty teaching style and academic performance in Christian secondary School in Southern California Talbot school of Theology. (Dissertation Abstracts International ), Biola University, Biola University. 